occur and a liquid polysulphide melt could be exposed at the surface on evaporation of the overlying sulphur. Sodium polysulphide lakes or remnants of such lakes may occur in the Loki Patera region and elsewhere on Io and could be distinguished from convecting sulphur lakes using infrared observations at several wavelengths. Lunine and Stevenson suggest that such polysulphide lakes could be the source for the sodium-enriched material in the Io torus.

Although many assumptions are involved, Lunine and Stevenson's rigorous application of theory to both Earth-based and Voyager observations demonstrates the importance of continued monitoring of Io from Earth and is an example of the type and quality of work necessary to plan future observations effectively. In particular, the sulphur lake model can be evaluated during the Galileo mission in the 199()s. Lunine and Stevenson suggest that during the cruise phase of each orbit thermal measurements, including those from the night side of Io, could be used to characterize and to detect variations in hot-spot activity.

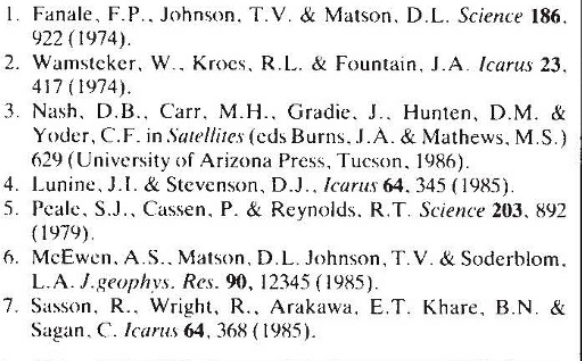

David A. Crown and Ronald Greeley are in the Department of Geology, Arizona State University, Tempe, Arizona 85287, USA.

\title{
Plant viruses
}

\section{New threats to crops from changing farming practices}

\section{from Robert Coutts}

IN THE 25 years since it was first suggested that root-inhabiting fungi act as vectors of plant viruses', many such viruses have been identified and some characterized in detail (see ref. 2 for a recent review). The importance of these viruses as plant pathogens in the United Kingdom was largely ignored until recent changes in agricultural practice as well as the geographical proximity of the fungus-vectored viral agent of rhizomania, beet necrotic yellow-vein virus, renewed interest ${ }^{3}$. Will an increased awareness of the incidence of soil-borne viruses or further changes in agricultural practice result in the appearance of further 'new' viruses and their associated diseases?

Of immediate concern to farmers in the United Kingdom is the spread of barley yellow mosaic virus ${ }^{1.5}$ carried by zoospores of the primitive plasmodiophoromycyte Polymyxa graminis Ledingham, that affects winter barley. (Beet necrotic

\section{IMAGE UNAVAILABLE FOR COPYRIGHT REASONS}

Infected barley root cell full of resting spores (cystospori) of $P$. graminis, the vector of barley yellow mosaic virus. (Photograph courtesy of E.J.F. Roberts and K.G. Laing.) yellow-vein virus is transmitted by another member of this group, $P$. betae Keskin.) The barley virus is widespread, causing variable reductions in grain yield, because farmers now grow winter malting barley as a profitable spring crop. Local soil conditions, such as low temperature and high humidity, are ideal for fungus transmission of the virus and the development of symptoms. As temperatures rise in the spring the symptoms of the disease fade but infected plants remain stunted.

After transmitting the virus to the plants, the zoospores develop into cystosori which are found in the roots and which can remain viable for extended periods (see figure). This feature of the fungal life-cycle ensures perpetuation of the fungus and virus in areas of intensive winter barley production. Recent reports of the incidence of more than one naturally occurring strain of the virus ${ }^{\natural}$ suggests any inbred resistance may not be durable.

In the long term, biological control of Polymyxa with other rhizosphere-inhabiting microorganisms may be possible. For example, cystosori of $P$. betae can be parasitized and completely degraded by Trichoderma harzianum Rifai in vitro ${ }^{\dagger}$. offering hope for the control of rhizomania, the sugar-beet disease that causes havoc in Europe. This disease and the causal agent, beet necrotic yellow-vein virus, have recently been diagnosed in France, the Netherlands, Belgium and Luxembourg. Import of sugar-beet stecklings from Europe to the United Kingdom is now banned ${ }^{3}$.

$P$. graminis and $P$. betae can be differ- entiated only by host specificity, and the spread and transmission of the beet and barley viruses described here appears similar. A recent survey ${ }^{8}$ failed to find the beet virus or the disease in the United Kingdom but does reveal the presence of a morphologically similar but serologically distinct virus". This virus, or one very similar to it, had been isolated previously from beet plants in Norfolk displaying root-symptoms of the Barney patch disorder. The virus, provisionally named beet soil-borne virus, is also apparently transmitted by $P$. betae but its pathogenic effects, if any, are unknown. The catastrophic effects of rhizomania are well documented, with the sugar content of infected beets reduced to 10 per cent or less of that found in uninfected controls ${ }^{3}$.

Changes in horticultural practice have increased the incidence of another group of fungus-borne viruses whose appearance coincides with the increased growing of plants in soil-free environments, where plants are cultivated on solid-support matrices and fed with liquid nutrients. Nutrient-film growing is popular with growers for several reasons, such as its application to greenhouse crops, ease of maintenance, monitoring of nutrient supply, quality control and cost. But two outbreaks of disease in the last six years, lettuce big vein virus" and necrotic spot virus in cucumber ${ }^{110}$ seem to be a direct result of nutrient-film growing.

The lettuce and cucumber viruses are transmitted by zoospores of the aquatic phycomycetes Olpidium brassicae and $O$. radicale. respectively. However dissimilar from the situation with the plasmodiophoraceous fungi, chemical control of phycomycete fungi and the diseases they transmit appears feasible - the two outbreaks of lettuce and cucumber viruses were successfully controlled by continuous application of a non-ionic liquid surfactant that killed the transmitting zoospores ${ }^{4,110}$.

It is unlikely that the viruses I have described in this article are new to the United Kingdom. It is more plausible that interactions between the viruses, vectors and hosts are now acting under the correct environmental conditions for infection to result.

\footnotetext{
Teakle. D.S. Nature 188, 43 I (1960).

2. Brunt. A.A. \& Shikata. E. in The Rod-shaped Plan Viruses (ed. van Regenmortal. M.H.V.) (Plenum. New York. in the press)

Dunning. R A. Brit Sugar Beet Rev. 52, 47 (1984).

t. Adams. M.J. Rothamsted A. Rep. Part 1130 (1984).

. Hill. S. A. Plant Path. 29. 197 (1980).

Ehlers. U. \& Paul. H.-L. J. Phytopath. 115. 294 (1986)

7. D Ambra. V. \& Mutto, S. J. Phytopath. 115.61 (1986).

8. Henry. C.M.. Jones. R.A.C. \& Coutts. R.H.A. Plant Path. (in the press)

9. Tomlinson, J.A.\& Faithfull. E.M. Anm. Appl. Biol. 93. 13 (1979).

11). Tomlinson. J.A. \& Thomas. B.J. Ann. Appl. Biol. 108. 71 (1986).
}

Robert Coutts is Lecturer in Plant Virology in the Department of Pure and Applied Biology. Imperial College, London SW7 $2 B B, U K$. 